\title{
Diagnosis and Treatment of a Typical Painful Neuropathy Due to "Insulin Neuritis" in Patients with Diabetes
}

\author{
Amir Aslam ${ }^{1}$, Satyan Rajbhandari ${ }^{2,3}$ and Jaipaul Singh ${ }^{3 *}$ \\ ${ }^{1}$ Eaton Centre Medical Clinic, Canada \\ ${ }^{2}$ Department of Diabetes and Endocrinology, Lancashire Teaching Hospital NHS Trust, UK \\ ${ }^{3}$ School of Pharmacy and Biomedical Sciences and School of Forensic and Investigative Sciences, University of Central Lancashire, UK
}

Submission: March 23,2018; Published: September 21, 2018

*Corresponding author: Jaipaul Singh, School of Pharmacy and Biomedical Sciences and School of Forensic and Investigative Sciences, University of Central Lancashire, Preston, PR1 2HE, Lancashire, England, UK, Tel: 00441772 893515; Email: jsingh3@uclan.ac.uk

\begin{abstract}
Diabetes is very common and its global prevalence is rising day by day. As a result we are seeing more complications related to diabetes. In order to prevent micro vascular and macro vascular complications such as retinopathy, nephropathy, erectile dysfunction, neuropathy, myocardial infarction and stroke health care professionals are keen to have better glycaemic control. When dealing with newly diagnosed or poorly controlled diabetes patients are encouraged to bring down glycated haemoglobin (HbA1c). Diabetic painful neuropathy (DPN) is one of the well-known complications associated with long- term poor glycaemic control. However, on the other hand rapid control of high blood sugar can precipitate painful neuropathy known as "insulin neuritis". The rapid tight glycaemic control with either insulin or oral hypoglycaemic agents on poorly controlled diabetic patients cause flux of blood glucose and metabolic shift resulting in structural changes at nerve endings (endoneural blood vessels) which resemble the retinopathy changes in retina. It causes steal effect and hypoxia in the nerves and hence precipitates neuropathic pain. It lasts for about 6 months and responds well to standard treatment of painful neuropathy. Health professionals need to be aware of this condition and consider gentle glycaemic control when aiming for Target HbA1c. This review outlines the disease, the symptoms, the types and treatment.
\end{abstract}

Keywords: Insulin neuritis; Diabetes mellitus; Glycaemic control; Neuropathy; Retinopathy; Blood glucose

\section{Introduction}

Diabetes mellitus (DM) is the commonest metabolic disease currently affecting more that 250 million people worldwide and it costs the Governments of the world more than £800billion to diagnose, treat and care for diabetic patients. DM is associated with numerous long-term complications including cardiomyopathy, nephropathy, neuropathy and retinopathy. This review addresses diabetic painful neuropathy (DPN) which is one of the well-known complications of diabetes and it affects up to $53 \%$ of diabetic population [1]. It is the most common form of painful neuropathy [2]. It manifests with varying description from mild pins and needle sensation to the stabbing pain, burning, unremitting or even described as electric shock. The most common feature is cutaneous hypersensitivity leading to acute distress on contact with an external stimulus, such as clothing [3]. The pathogenesis of DPN is mainly caused by inflammatory process [4] and strongly correlates with longer duration of the diabetes and poor glycaemic control [5-18].
Treatment induces acute neuropathy due to rapid glycaemic control has been reported in literature as 'insulin neuritis' that usually manifests with severe excruciating neuropathic pain in the first month of initiation of insulin or oral hypoglycaemic agents. Symptoms usually last up to 6 months and respond to treatment that is usually needed up to 6 months [3]. Insulin neuritis was first described by Caravati [19] in 1933. He reported a diabetic woman with numbness, tingling, and shooting pains in the lower extremities that appeared four weeks after the initiation of insulin. The pain increased despite the use of analgesics and sedatives, but resolved within 3 days of stopping insulin concurrent with severe hyperglycaemia. Further attempts at the use of insulin resulted in similar levels of pain. He called the condition "insulin neuritis" [19]. The word insulin neuritis is a misnomer, as it can also be induced by oral hypoglycaemic agent [20]. The cause is not directly by insulin but mainly due to the change in flux of blood glucose caused by 


\section{Open Access Journal of Neurology \& Neurosurgery}

rapid change in blood glucose level following pharmacological treatment [21].

\section{Symptoms}

There are several studies and case reports in the literature about insulin neuritis with varying presentation after starting insulin or oral hypoglycaemic agents. These reports described the most common features as generalized pain bilaterally mainly distally in feet with burning sensation, hypersensitivity and contact discomfort of the skin within 2 to 4 weeks $[20,22,23]$. It may present with truncal neuropathy [24-27], autonomic neuropathy [28], worsening of retinopathy [29], and even with profound weight loss [22,30-32].

\section{Generalize pain mainly distally}

The most common presentation of Insulin neuritis is symmetrical and bilateral distal neuropathic pain mainly involving feets [3]. In one observational study on 6 patients with diabetes, all experienced severe excruciating bilateral neuropathic pain mainly in feet after 2-4 weeks of insulin treatment with rapid reduction of blood glucose up to one fifth of initial levels. This improved in all cases with symptomatic treatment allowing discontinuation of therapy in 3-8 months [20]. A case report on a newly diagnosed type 1 diabetes patient described development of severe pain in his feet, which prevented him from walking, after initiation of insulin. The HbA1c of that patient dropped from 14.1 to $7.6 \%$, and 3 months after presentation, the patient showed dramatic improvement and regained his ability to walk [33]. There is another similar case report of painful neuropathy on 15th day of treatment with intense insulin therapy following poor glycaemic control period of 8 years. He responded well on symptomatic treatment on day 3 on venlafaxine [34].

\section{Diabetic neuropathic cachexia}

Painful neuropathy is sometimes associated with profound weight loss and called "Diabetic neuropathic cachexia". This has also been reported with insulin neuritis that could last up to a year. The exact mechanism and cause is unknown [3]. It is observed that constant pain and discomfort can cause loss of appetite and low mood which results in patients not eating enough and start losing weight. Most patients respond well with neuropathic pain treatment which gives pain relief and regain weight. In one observational study, 9 diabetic patients experienced painful neuropathy with constant burning pain mainly in the legs, especially distally. There was marked troublesome allodynia associated with profound weight loss along with depression with impotence. These severe manifestations subsided in most cases in 6 months and in all cases in 10 months [22]. There is another case report in which patient presented with painful neuropathy, profound weight loss after initiation of insulin therapy within 3 months [31].

\section{Truncal neuropathy}

Insulin neuritis may precipitate focal neuropathic pain called "Truncal neuropathy" on specific dermatome region. Truncal neuropathy in diabetes presents with neuropathic pain such as a hypoesthesia, regional hyperalgesia, allodynia and sometime focal weakness in specific dermatome region. It usually presents with unilateral abdominal or thoracic wall pain $[3,25]$. There was one case of insulin neuritis which presented with painful neuropathy with paraesthesia and hyperesthesia restricted to the abdomen and this was associated with profound weight loss. The haemoglobin A (1c) had dropped from $12 \%$ to $7.5 \%$ within 5 months, following rapid improvement in glycaemic control. On investigation, there was no indication of disease in intraabdominal area. The symptoms improved dramatically within 4 months after symptomatic treatment [30].

It is not uncommon that these patients have to undergo a number of investigations to determine the cause of pain before having the diagnosis of truncal neuropathy [24-27,30]. There are several cases of truncal neuropathy that were misdiagnosed initially as for example hernia due to focal weakness on abdominal wall [26], angina due to left sided chest wall pain [25] and painless gall stones due to focal sensory deficit complicated with painless jaundice secondary gall stone [27]. The diagnosis of truncal neuropathy is essentially clinical and positive recognition of neuropathic element of pain is the key factor. Most people respond well on neuropathic treatment and usually settle in 3 to 12 months.

\section{Autonomic neuropathy}

Autonomic dysfunction is one of the complications of diabetes3. It manifests with one or more of the following: erectile dysfunction, gatsroparesis, neurogenic bladder, dry feet, depressed cough reflex, postural hypotension or high blood flow to foot $[35,36]$. Insulin neuritis has been reported to precipitate autonomic neuropathy. In one prospective study on 16 diabetic patients followed up for 18 months, all the patients develop severe painful neuropathy in 8 weeks of intense glycaemic treatment. All individuals with treatment for induced neuropathy had evidence of autonomic dysfunction on testing and exhibited symptoms of autonomic impairment. Approximately, 69\% of cohort had systolic blood pressure falls $>20 \mathrm{mmHg}$. Symptoms of autonomic dysfunction were more prevalent and more severe in subjects with type 1 diabetes, particularly with respect to symptoms of orthostatic intolerance and gastrointestinal function. Urinary frequency, nocturia and anhidrosis were reported more frequently in individuals with type 2 diabetes [28].

\section{Retinopathy}

Retinopathy is a well-known complication of diabetes and directly related with poor glycaemia and duration of diabetes 


\section{Open Access Journal of Neurology \& Neurosurgery}

[37]. It is also proven that better glycaemic control prevent worsening of retinopathy [38]. Insulin neuritis with rapid flux of blood glucose causes structural changes at endoneural blood vessels of nerves which resemble with retinopathic changes in retina [39]. Rapid drop in blood glucose in poorly controlled diabetes may exert the same changes in retina, thus worsening the retinopathy. In one large observational study, 87 patients were divided in 3 groups of varying glycaemic control. These included a group of poor glycaemic control corrected rapidly, poor glycaemic control not corrected and good control group. The progression rate of diabetic maculopathy was significantly higher in the group that underwent rapid control than in the other 2 groups $(\mathrm{P}<02)$. Patients with moderate to severe nonproliferative diabetic retinopathy preoperatively in the rapid control group had significantly higher progression rates of diabetic retinopathy and maculopathy $(P<002$ and $p<008$, respectively) [40].

\section{Pathogenesis}

In 1992 Boulton first described the observation that acute painful neuropathy might follow sudden change in glycaemia control suggesting that blood glucose flux could precipitate pain. Sudden changes in glycaemia may contribute to the generation of impulses or even induce relative hypoxia in nerve fibres, indicating that it is the combination of structural and functional changes in peripheral nerves which cause the pain [21]. This observation was experimentally tested by Kihara et al. [41] in 1994 on rats. In their study, they infused insulin under non- hypoglycaemic conditions and evaluated its effect on endoneurial oxygen tension, nerve blood flow, and the oxy-haemoglobin dissociation curve of peripheral nerves in normal and diabetic rats. Their results showed that insulin administration could cause a reduction in nerve nutritive blood flow and an increase in arterio-venous shunt flow. When the latter was eliminated by the closure of arterio-venous shunts (infusion of 5-hydroxytryptamine), endoneurial oxygen reverted to normal. These findings clearly indicate a deleterious vasoactive effect of insulin and may explain the development of insulin neuritis [41].

In 1996 Tesfaye et al observed neurovascular changes in vivo in five human diabetic patients with insulin neuritis. These patients presented with severe sensory symptoms but clinical examination and electrophysiological tests were normal except with one subject who had severe autonomic neuropathy and all tests were abnormal. On sural nerve exposure in vivo, epineural blood vessels showed severe structural abnormalities resembling the retinopathy changes normally seen in the retina, including arteriolar attenuation, tortuosity and ateriovenous shunting and proliferating new vessels formation. They hypothesized that the structural abnormalities with new vessels formation in epineural blood vessels cause steal effect and hence results in hypoxia and neuropathic pain [39]. It can now be postulated that sudden change in glycaemic control can cause flux effect resulting in structural and functional changes at the epineural blood vessels of nerves which in turn can lead to neuropathic pain "Insulin neuritis (Figure 1)" [21,39].

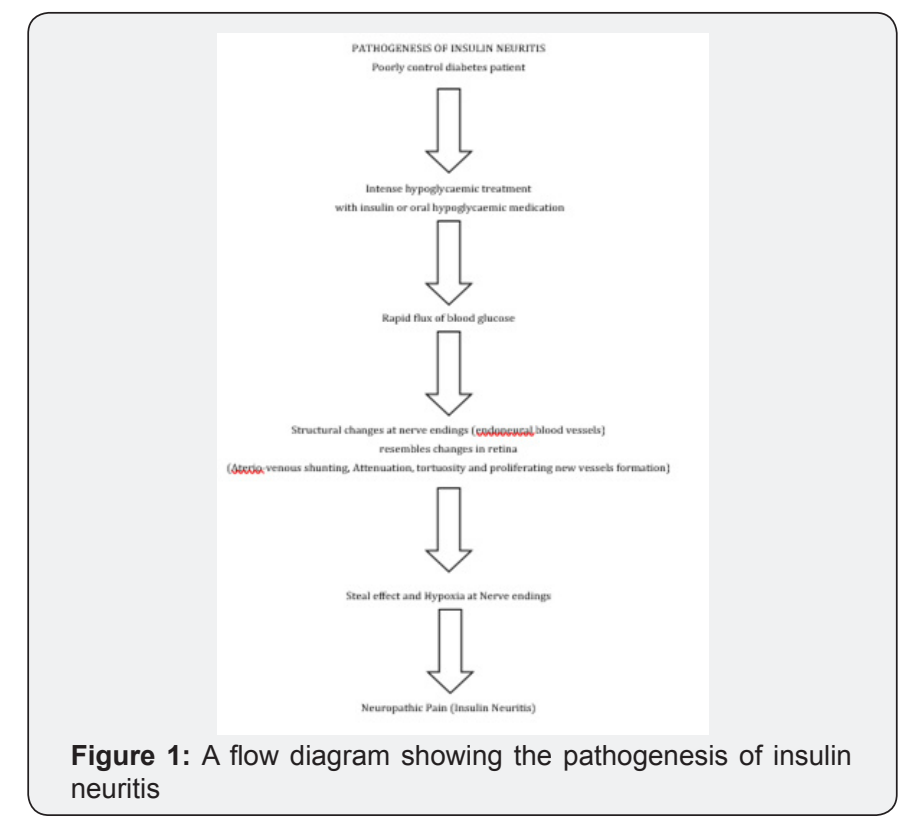

Treatment

Management of neuropathic pain in "insulin neuritis" is symptomatic including first line medication tricyclic antidepressants (Amitriptyline) or selective serotonin uptake inhibitor (Duloxetine). Second line medications include antiepileptic medications (Gabapentin, Pregabalin, Carbamazepine and Topiramate) and Opioids. Most patients recover within 6 months of onset of insulin neuritis [3].

\section{Conclusion}

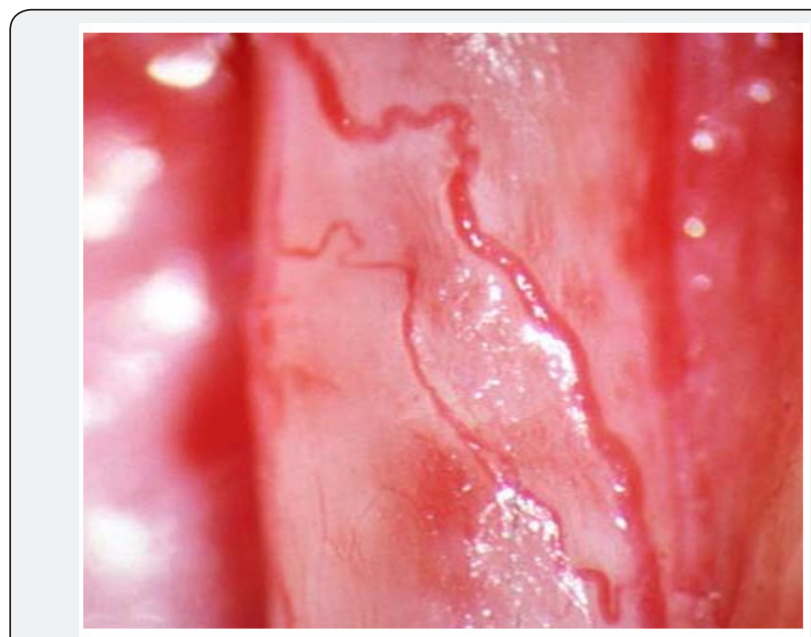

Figure 2: Arteriolar attenuation, tortuosity and ateriovenous shunting and proliferating new vessels formation of vasanervosum seen in sural nerve of patient with insulin neuritis (photo courtesy of Tesfaye and Boulton [9]).

The flow diagram in Figure 2 summarises the pathogenesis of insulin neuritis. With increasing prevalence of diabetes and its complications, both health professional and patients are keen to have good glycaemic control in order to prevent long term 


\section{Open Access Journal of Neurology \& Neurosurgery}

complications [42]. Most of the time it is not a problem but on several occasions intense treatment for rapid glycaemic control may cause insulin neuritis. This is presumed to be caused by change in glucose flux which can result in structural and functional changes at the nerves leading to hypoxia. This in turn can precipitate neuropathic pain and the whole phenomenon is called "insulin neuritis". It usually manifests distally in feet and is bilateral with burning sensation, hypersensitivity and allodynia. It could affect focally - truncal neuritis and may present with neuropathic pain and/or weakness in dermatomal region. Similarly, it may present with autonomic symptoms. Constant pain may cause cachexia and loss of appetite which can result in significant weight loss. Most patients respond well with neuropathic treatment and recover within 6 months. It is very important to be aware that treatment induced insulin neuritis can have significant impact on the quality of the life of the diabetic patient. This can be easily prevented by gradual glycaemic control and by symptomatic treatment as necessary. Healthcare professionals need to be aware of this condition when managing poorly controlled diabetic patients and should consider gradual titration of the pharmacological agents employed to treat the patients.

\section{References}

1. Mimi O, Teng CL, Chia YC (2003) The prevalence of diabetic peripheral neuropathy in an outpatient setting. The Medical Journal of Malaysia 58(4): 533-538.

2. Chong MS and Hester J (2007) Diabetic painful neuropathy: current and future treatment options, Drugs 67(4): 38-45.

3. Larsen, Kronenberg, et al. (2002) Williams Textbook of Endocrinology. Tenth edition Saunders, Elsevier Science. Philadelphia.

4. Said G (2007) Diabetic neuropathy - A Review. National Clinical Practice and Neurology 3(6): 331-340.

5. Shaw JE, Hodge AM, de Courten M, Dowse GK, Gareeboo H, et al. (1998) Diabetic neuropathy in Mauritius: prevalence and risk factors. Diabetes Research and Clinical Practice 42(2): 131-139.

6. Börü UT, Alp R, Sargin H, Koçer A, Sargin M, et al. (2004) Prevalence of peripheral neuropathy in type 2 diabetic patients attending a diabetes centre in Turkey. Endocrine Journal 51(6): 563-567.

7. Walters DP, Gatling W, Mullee MA, Hill RD (1992) The prevalence of diabetic distal sensory neuropathy in an English community. Diabetic Medicine 9(4): 349-353.

8. Abbott CA, Malik RA, van Ross ER, Kulkarni J, Boulton AJ (2011) Prevalence and characteristics of painful diabetic neuropathy in a large community-based diabetic population in the UK. Diabetes care 2011; 34(10): 34-48.

9. Tesfaye S, Boulton A (2009) Diabetic neuropathy, Oxford University Press, United States, first edition, pp 8-56.

10. Erbas T, Ertas M, Yucel A, Keskinaslan A, Senocak M (2011) Prevalence of peripheral neuropathy and painful peripheral neuropathy in Turkish diabetic patients. Journal of Clinical Neurophysiology 28(1): 51-55.

11. Jambart S, Ammache Z, Haddad F, Younes A, Hassoun A, et al. (2011) Prevalence of painful diabetic peripheral neuropathy among patients with diabetes mellitus in the Middle East region. Journal of International Medical Research 39(2): 366-377.
12. Kästenbauer T, Irsigler P, Sauseng S, Grimm A, Prager R (2004) The prevalence of symptoms of sensorimotor and autonomic neuropathy in Type 1 and Type 2 diabetic subjects. Journal of Diabetes and Its Complications 18(1): 27-31.

13. Dyck PJ, Kratz KM, Karnes JL, Litchy WJ, Klein R, et al. (1993) The prevalence by staged severity of various types of diabetic neuropathy, retinopathy, and nephropathy in a population-based cohort: the Rochester Diabetic Neuropathy Study. Neurology 43(4): 817-824.

14. Maser RE, Steenkiste AR, Dorman JS, Nielsen VK, Bass EB, et al. (1989) Epidemiological correlates of diabetic neuropathy. Report from Pittsburgh Epidemiology of Diabetes Complications Study. Diabetes 38(11): 1456-1461.

15. Pradeepa R, Rema M, Vignesh J, Deepa M, Deepa R, et al. (2008) Prevalence and risk factors for diabetic neuropathy in an urban south Indian population: the Chennai Urban Rural Epidemiology Study (CURES-55). Diabetic Medicine 25(4): 407-412.

16. Fedele D, Comi G, Coscelli C, Cucinotta D, Feldman EL, et al. (1997) A multicenter study on the prevalence of diabetic neuropathy in Italy. Italian Diabetic Neuropathy Committee. Diabetes Care 20(5): 836-843.

17. Hsu WC, Yen AM, Liou HH, Wang HC, Chen TH (2009) Prevalence and risk factors of somatic and autonomic neuropathy in prediabetic and diabetic patients. Neuroepidemiology 33(4): 344-349.

18. Morkrid K, Ali L, Hussain A (2010) Risk factors and prevalence of diabetic peripheral neuropathy: A study of type 2 diabetic outpatients in Bangladesh. International Journal of Diabetes in Developing Countries 30(1): 11-17.

19. Caravati CM (1933) Insulin neuritis: a case report. Va Med Monthly 59: 745-746.

20. Dabbya R, Sadeha M, Yair Lampla, Gilad R, Watemberg N (2009) Acute painful neuropathy induced by rapid correction of serum glucose levels in diabetes patients. Biomedicine and Pharmacotherapy 63 (10): 707-709.

21. Boulton A (1992) What causes neuropathic pain? Journal of Diabetes and its Complication 6(1): 58-63.

22. Archer A, Watkins PJ, Thomas PK (1983) The natural history of acute painful neuropathy in diabetes mellitus. Journal of Neurology Neurosurgery Psychiatry 46(6) :491-499.

23. Leow MKS, Wyckoff J (2005) Under-recognised paradox of neuropathy from rapid glycaemic control. Postgraduate Medical Journal 81(952): 103-107.

24. Takayama S, Takahashi Y, Osawa M (2004) Acute Painful Neuropathy Restricted to the Abdomen Following Rapid Glycaemic Control in Type 2 Diabetes. The Journal of International Medical Research 32(5): 558562.

25. Ibitoye R, Rajbhandari SM (2012) Neuropathic truncal pain - a case series. Q J Med 105(10): 1027-1031.

26. Parry G, Floberg J (1989) Diabetic truncal neuropathy presenting as abdominal hernia. Neurology 39(11): 1488-1490.

27. Gentile S (1994) Asymptomatic choledocholithiasis associated with diabetic neuropathy. Report of a case. La Clinica Terapeutica 144(5): 461-465.

28. Gibbons CH, Freeman R (2010) Treatment-induced diabetic neuropathy: a reversible painful autonomic neuropathy. Annals of Neurology 67(4): 534-541.

29. Suto C, Hori S, Kato S, Muraoka K, Kitano S (2006) Effect of Perioperative Glycemic Control in Progression of Diabetic Retinopathy and Maculopathy. Archives of Ophthalmology 124(1): 38-45. 


\section{Open Access Journal of Neurology \& Neurosurgery}

30. Van Heel DA, Levitt NS, Winter TA (1998) Diabetic neuropathic cachexia: the importance of positive recognition and early nutritional support. International Journal Clinical Practice 52(8): 591-592.

31. Yuen1 KCJ, Day JL, Flannagan DW, Rayman G (2001) Diabetic neuropathic cachexia and acute bilateral cataract formation following rapid glycaemic control in a newly diagnosed Type 1 diabetic patient Diabetic Medicine 18(10): 854-857.

32. Knopp M, Rajabally YA (2012) Common and Less Common Periphera Nerve Disorders Associated with Diabetes. Current Diabetes Reviews 8(3): 229-236(8)

33. Wilson JL, Sokol DK, Smith LH, Snook RJ, Waguespack SG, et al (2003) Acute painful neuropathy (insulin neuritis) in a boy following rapid glycemic control for type 1 diabetes mellitus. Journal of Child Neurology 18(5): 365-367.

34. Guldiken S, Guldiken B, Arikan E, Altun Ugur B, Kara M, et al. (2004) Complete relief of pain in acute painful diabetic neuropathy of rapid glycaemic control (insulin neuritis) with venlafaxine HCL. Diabetes, Nutrition and Metabolism - Clinical and Experimental 17(4): 247-259.

35. Watkins (2003) ABC of Diabetes, BMJ Publishing Group London, Fifth Edition, pp 32-37.

36. Galer, Gianas, Jensen (2000) Painful diabetic polyneuropathy: epidemiology, pain description, and quality of life. Diabetes Research and Clinical Practice 47(2): 123-128.

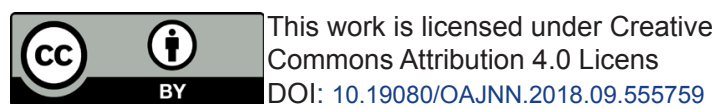

37. Stratton IM, Kohner EM, Aldington SJ, Turner RC, Holman RR, et al. (2001) UKPDS 50: risk factors for incidence and progression of retinopathy in Type II diabetes over 6 years from diagnosis Diabetologia 44(2): 156-63.

38. Holman R, Paul S, Bethel A, Matthews D, Neil A (2008) 10-Year Followup of Intensive Glucose Control in Type 2 Diabetes. New England Journal of Medicine 359: 1577-1589.

39. Tesfaye S, Malik R, Harris N, Jakubowski JJ, Mody C, et al. (1996) Arterio-venous shunting and proliferating new vessels in acute painful neuropathy of rapid glycaemic control (insulin neuritis). Diabetologia 39(3): 329-335

40. Suto C, Hori S, Kato S, Muraoka K, Kitano S (2006) Effect of Perioperative Glycemic Control in Progression of Diabetic Retinopathy and Maculopathy. Arch Ophthalmol 124(1): 38-45.

41. Kihara M, Zollman PJ, Smithson L, Lagerlund TD, Low PA (1994) Hypoxic effect of exogenous insulin on normal and diabetic peripheral nerve. American Journal of Physiology 266(6 Pt 1): E980-E985.

42. Williams J, Alling K (1980) A Program for Normal Glycemic Control of Insulin dependent Diabetes. Diabetes Care 3(1): 160-162.

Your next submission with Juniper Publishers
will reach you the below assets
- Quality Editorial service
- Swift Peer Review
- Reprints availability
- E-prints Service
- Manuscript Podcast for convenient understanding
- Global attainment for your research
- Manuscript accessibility in different formats
( Pdf, E-pub, Full Text, Audio)
- Unceasing customer service
Track the below URL for one-step submission
https://juniperpublishers.com/online-submission.php

